\title{
DILUTE SOLUTION PROPERTIES AND MOLECULAR CHARACTERIZATION OF POLYVINYL CHLORIDE
}

\author{
A. J. De Vries, C. Bonnebat and M. Carrega \\ Péchiney-Saint-Gobain, Centre de Recherches de la Croix-de-Berny, \\ 182 Avenue Aristide Briand, 92-Antony-France
}

\begin{abstract}
Dilute solution properties of twenty-five PVC fractions prepared from commercial and experimental bulk-polymerized PVC samples have been investigated by means of light-scattering, viscometry and exclusion-chromatography. The following Mark-Houwink-Sakadura relationships :

$$
\begin{aligned}
& {[\eta]_{\mathrm{THF}}^{25^{\circ} \mathrm{C}}=1.6310^{-2} M_{w}^{0.760} \times 1.017 \text { c.g.s. }} \\
& {[\eta]_{\text {cyclohexanone }}^{25^{\circ} \mathrm{C}}=2.5710^{-2} M_{w}{ }^{0.725} \times 1.02 \text { c.g.s. }}
\end{aligned}
$$

have been found to be valid in a range of $M_{w}$-values between 6400 and 650000 . The validity of various extrapolation procedures, proposed in order to calculate unperturbed dimensions and polymer-solvent interaction parameters from the empirical viscosity-molecular weight relationship, has been examined. The Kurata-Stockmayer method applied to the measurements in tetrahydrofuran yields a $K_{\theta}$-value equal to $0.14 \mathrm{c.gs}$. The polymer-solvent interaction parameter derived by the same method is not in agreement with the one deduced from second virial coefficient measurements.

Molecular weight distributions determined in commercial PVC samples can be adequately represented, in a first approximation, by the usual exponential distribution function, first proposed by Schulz. The chromatographic determination of MWD and its effect on the viscosity-molecular weight relationship are discussed.

Finally, the possible occurrence of long chain branching in PVC has been investigated by means of an experimental study of the structure and properties of various polyethylene samples obtained by reduction with $\mathrm{LiAlH}_{4}$ of commercial PVC polymers. The melting temperatures and the intrinsic viscosity -molecular weight relationship for the polyethylene samples, so obtained, were found to be identical with those of High Density Polyethylene. It is concluded that most PVC polymers contain only very few long branches, if any.
\end{abstract}

\section{INTRODUCTION}

Dilute solution properties of polymers may provide quantitative information on the size, shape and structure of the dissolved macromolecules as well as on the importance of polymer-polymer and polymer-solvent 
interactions. A considerable number of experimental studies in this field have been reported in the literature but only a few of them are concerned with poly (vinyl chloride) in spite of the ever increasing technological and economical interest of this polymer. In a series of papers published by Kratochvíl, Bohdanecký, Kolínský and others ${ }^{1-4}$ the various anomalies observable in studies of the dilute solution properties of PVC are discussed in a detailed manner. The same authors also show that representative and reproducible results can only be obtained under well-controlled conditions, taking account of the notorious tendency of PVC molecules to remain partly associated in supermolecular aggregates even if dissolved in a good solvent. The presence of aggregates which only disappear after prolonged heating of the solution, at a sufficiently high temperature, is usually attributed to the semi-crystalline nature of PVC. Although the degree of crystallinity is rather low, the melting temperature of the crystallites is relatively high $^{5,6}$ which may well explain the difficulty of obtaining real molecular solutions. Bohdanecký ${ }^{7}$ has recently provided some quantitative evidence in favour of this explanation by applying Flory's theory of melting-point depression ${ }^{8}$ to the case of PVC solutions. On the other hand, moderate heating of PVC solutions in tetrahydrofuran (THF), the most suitable solvent known, may sometimes lead to reversible aggregation ${ }^{9}$. Thus a proper choice of temperature and concentration is of utmost importance.

Neglect of the experimental conditions required to obtain molecular solutions is undoubtedly the main reason for the discrepancies between the results reported on similar polymer samples by different laboratories. The inter-laboratory programme ${ }^{10}$ recently organized by Professor $\mathrm{H}$. Benoit (Chairman of the Working Party on Molecular Characterization of Commercial Polymers, Macromolecular Division IUPAC) has shown quite clearly, however, that fair agreement can be obtained between the results obtained in different laboratories, on the same sample of a typical commercial PVC resin, with regard to intrinsic viscosity, average molecular weights, and molecular weight distribution, determined with the aid of several experimental techniques. Although the agreement between the different laboratories is only fair and still far from being perfect, it is significantly better than the results obtained in the same programme for other types of commercial polymers; even for polystyrene, a polymer often believed to furnish the most reliable results if studied by dilute solution techniques. It appears, therefore, justifiable to consider the results of dilute solution measurements on PVC samples to be at least as reliable as those obtained with other synthetic polymers, provided sufficient care has been taken in preparing the solutions. A serious drawback for a complete study of the dilute solution properties of PVC remains, however, in the limited choice of solvents. Cyclohexanone is most frequently used for viscosity measurements. According to our experience, based on the results of light-scattering measurements, THF is the most appropriate solvent if one wants to avoid the presence of aggregates which may only slightly affect the results of viscosity measurements but which may give rise to serious errors if one wants to determine average molecular weights and molecular weight distribution, with the use of appropriate experimental techniques.

The greater part of the results reported here have been obtained using 
THF as the solvent; in view of the widespread use of cyclohexanone some results obtained with the latter solvent are also given. The first part of this report is mainly concerned with measurements carried out on PVC fractions of relatively low polydispersity and the results are analyzed with respect to current theories of dilute polymer solutions. In the second part we discuss the use of dilute solution measurements for the molecular characterization of commercial samples of PVC.

All samples used in this investigation have been prepared from bulkpolymerized PVC, most of it taken from the commercial production of the Péchiney-Saint-Gobain plant in St. Fons, France. Some of the samples having extremely low or high molecular weights have been prepared in the laboratory by means of bulk polymerization in small autoclaves.

All parameters used in this report (including the intrinsic viscosities) are expressed in c.g.s. units.

\section{EXPERIMENTAL}

\section{Fractionation}

(a) Fractions with weight-average molecular weights, $M_{w}$, between 60000 and 300000 have been prepared from a commercial bulk-polymerized PVC, Lucovyl GB 1850, by means of successive precipitations, using THF as the solvent and distilled water as the precipitant; the latter was very slowly added to the solution containing $20 \mathrm{~g}$ of polymer and $2000 \mathrm{~cm}^{3}$ of THF until a slight turbidity appeared. The solution, placed in a thermostat at $25^{\circ} \mathrm{C}$ and stirred during the drop-wise addition of precipitant, was heated until disappearance of the turbidity and then left to cool for a period of 48 hours. The solution was then siphoned off and used for further fractionation. The precipitated polymer, most frequently in the form of a gelatinous mass, was redissolved in THF and poured into 5 to 10 times its volume of methanol. After filtration and washing, the fractionated polymer was finally dried in vacuo at $50^{\circ} \mathrm{C}$. Some of the higher molecular weight samples were refractionated a second time in order to reduce the polydispersity.

(b) Fractions with molecular weights larger than 300000 were prepared from an experimental polymer, RM 365, obtained by means of low-temperature polymerization $\left(-12^{\circ} \mathrm{C}\right)$, in a laboratory autoclave. The solvent was cyclohexanone, the precipitant glycol. The solution contained $5 \mathrm{~g}$ of polymer and $2500 \mathrm{~cm}^{3}$ of solvent and was heated for 5 hours at $85^{\circ} \mathrm{C}$ and 1 hour at $90^{\circ} \mathrm{C}$ before fractionation was effected at $25^{\circ} \mathrm{C}$. The first precipitated fraction (2g) was redissolved in cyclohexanone $\left(1000 \mathrm{~cm}^{3}\right)$ and refractionated.

(c) Fractions with weight-average molecular weights smaller than 60000 were prepared from an experimental polymer, RM 310 (bulk-polymerized at $60^{\circ} \mathrm{C}$ ), either by means of successive precipitations as described under (a) or by successive extractions using a mixture of THF and water. In the latter case the polymer was dispersed in the THF/water mixture and extracted for 5 hours at $40^{\circ} \mathrm{C}$ under stirring. After decantation, the fraction was recovered from the liquid phase by distillation of the solvent in vacuo. By means of this method fractions with weight-average molecular weights of the order of 6500 were obtained using a mixture of $2000 \mathrm{~cm}^{3}$ of THF and $450 \mathrm{~cm}^{3}$ of water. 


\section{A. J. DE VRIES, C. BONNEBAT AND M. CARREGA}

The polydispersity of a certain number of fractions was calculated from the molecular weight distribution determined by means of exclusion chromatography as described below. The ratio between weight-average and number-average molecular weight, $M_{w} / M_{n}$, was of the order of 1.2 for most of the fractions, the highest value being 1.32 and the lowest 1.12 .

The various experimental parameters determined on a total number of 25 fractions are given in Table 1.

Table 1. Experimental results obtained with PVC fractions

\begin{tabular}{|c|c|c|c|c|c|c|c|}
\hline Fractions & s No. & $M_{w} \times 10^{-3}$ & $\begin{array}{c}A_{2} \times 10^{3} \\
\mathrm{~m}^{3} \mathrm{~mol} / \mathrm{g}^{2}\end{array}$ & $\begin{array}{c}{[\eta]_{\mathrm{HHF}}^{25^{\circ} \mathrm{C}}} \\
\mathrm{cm}^{3} / \mathrm{g}\end{array}$ & $\frac{A_{2} M_{w}}{[\eta]_{\mathrm{THF}}}$ & $\frac{[\eta]_{\text {cyclo }}^{25 \mathrm{C}^{2}}}{\mathrm{~cm}^{3} / \mathrm{g}}$ & $\frac{M_{w}}{M_{n}}$ \\
\hline \multirow[t]{7}{*}{ RM 310} & 1 & 6.4 & $\ldots$ & 12.4 & - & & \\
\hline & 2 & 6.8 & - & 13.4 & - & & 1.14 \\
\hline & 3 & 13 & - & 22.0 & $\ldots$ & 24.2 & \\
\hline & 4 & 16 & 1.99 & 25.4 & 1.247 & & \\
\hline & 5 & 24 & 1.99 & 34.2 & 1.389 & 39.0 & \\
\hline & 6 & 32 & -- & 42.9 & - & & 1.17 \\
\hline & 7 & 44 & - & 55.1 & - & & \\
\hline \multirow[t]{17}{*}{ GB 1850} & 1 & 60 & 1.61 & 69.4 & 1.384 & & \\
\hline & 2 & 62 & - & 69.4 & - & & \\
\hline & 3 & 64 & - & 76.0 & $\ldots$ & & \\
\hline & 4 & 78 & 1.75 & 84.8 & 1.601 & & \\
\hline & 5 & 88 & 1.71 & 91.5 & 1.636 & & 1.22 \\
\hline & 6 & 94 & - & 8.1 & - & & \\
\hline & 7 & 107 & 1.68 & 109.1 & 1.633 & 116.1 & 1.20 \\
\hline & 8 & 115 & - & 110.2 & - & & \\
\hline & 9 & 125 & - & 121.2 & - & & 1.32 \\
\hline & 10 & 158 & - & 148.7 & - & & \\
\hline & 11 & 165 & $\ldots$ & 149.7 & - & 151.9 & 1.14 \\
\hline & 12 & 185 & 1.40 & $167 \cdot 4$ & 1.539 & & 1.12 \\
\hline & 13 & 205 & - & 176.3 & - & 182.0 & \\
\hline & 14 & 240 & 1.40 & 199.4 & 1.682 & & \\
\hline & 15 & 250 & - & 199.8 & - & & 1.28 \\
\hline & 16 & 253 & $1 \cdot 31$ & $212 \cdot 6$ & 1.550 & & \\
\hline & 17 & 310 & 1.35 & 231.4 & 1.806 & & \\
\hline RM 365 & 1 & 650 & - & 424.1 & - & 419.6 & \\
\hline
\end{tabular}

\section{Light-scattering}

All light-scattering measurements have been performed with Soficaphotometers, based on the design by Wippler and Scheibling ${ }^{11}$, at a wavelength of $5460 \AA$, and at 11 angles of observation ranging between 30 and $150^{\circ}$. Calibration was done by means of a benzene standard, adopting the value of $16.310^{-6} \mathrm{~cm}^{-1}$ for the Rayleigh ratio at $90^{\circ}$ at a temperature of $25^{\circ} \mathrm{C}$.

The solvent was freshly distilled THF and was added to the polymer in a glass tube which, after sealing, was heated in a slowly rotating oven for 4 hours at $110^{\circ} \mathrm{C}$. After this period of heating, the sealed tube containing the solution was quenched at $-80^{\circ} \mathrm{C}$ before opening The solution was then 


\section{SOLUTION PROPERTIES OF POLYVINYL CHLORIDE}

brought to room temperature and centrifuged at about $25000 \mathrm{~g}$ before the actual light-scattering measurements took place. Four or five different concentrations were used, the maximum concentration corresponding to an intensity of scattered light at $90^{\circ}$, which was about 3 to 4 times as high as the light intensity scattered by the solvent. All measurements were done at $25^{\circ} \mathrm{C}$

The results were plotted according to the method of $\mathrm{Zimm}^{12}$ and analyzed in terms of the familiar expressions:

$$
\begin{aligned}
& \left(\frac{K c}{R_{\theta}}\right)_{\theta \digamma 0}=\frac{1}{M_{w}}+2 A_{2} c \\
& \left(\frac{K c}{R_{\theta}}\right)_{c=0}=\frac{1}{M_{w}} P^{-1}(\theta)
\end{aligned}
$$

where $M_{w}$ is the weight-average molecular weight, $A_{2}$ the second virial coefficient and $P(\theta)$ the particle scattering function. The angle of observation is given by $\theta$ and the polymer concentration by $c$. The constant $K$ is proportional to the square of the refractive index increment; the latter has been taken equal to $0.112 \mathrm{~cm}^{3} / \mathrm{g}$. The scattering ratio $R_{\theta}$ can be calculated from the observed scattered light intensity after application of the usual corrections.

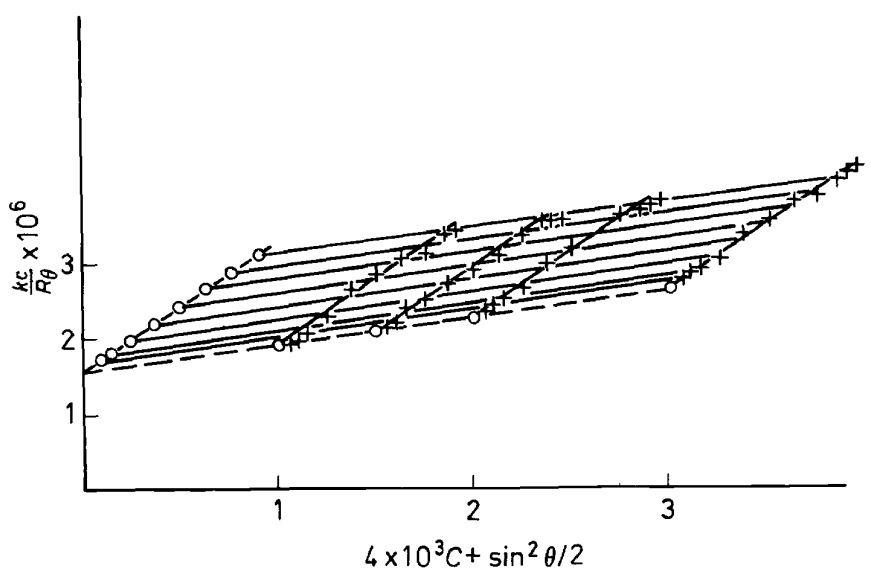

Figure 1. Zimm-plot for a PVC fraction of $M_{w}=650 \times 10^{3}$. Solvent: THF, maximum conc. $=7.5 \times 10^{-4} \mathrm{~g} / \mathrm{cm}^{3}$.

Figure 1 shows the Zimm-plot of the highest molecular weight fraction which we were able to investigate by means of the light-scattering method; the calculated value of $M_{w}$ is equal to 650000 . Solutions containing PVC molecules of such a high molecular weight are usually not very stable and liable to form aggregates, in particular at the highest concentrations. If such aggregates dissociate upon dilution, the concentration dependence of the scattered light intensity becomes abnormally high which may lead to an 


\section{A. J. DE VRIES, C. BONNEBAT AND M. CARREGA}

underestimation of the second virial coefficient calculated by means of Equation 1. The highest concentration used in the experiment of Figure 1 was $7.5 \times 10^{-4} \mathrm{~g} / \mathrm{cm}^{3}$.

\section{Exclusion chromatography}

Molecular weight distributions have been determined by means of exclusion chromatography, a technique more frequently designated by the name 'gel permeation chromatography'13, although the first term seems more appropriate ${ }^{14,15}$. The chromatographic system used was composed of a series of columns (internal diameter: $0.8 \mathrm{~cm}$ ) with a total length of 8 metres, packed with a mixture of different types of porous silica beads, 'Spherosil', whose properties have been described in earlier publications from this laboratory ${ }^{16-18}$. The solvent was THF and the volume of injected polymer solution (concentration $=5 \times 10^{-3} \mathrm{~g} / \mathrm{cm}^{3}$ ) equal to $0.5 \mathrm{~cm}^{3}$. Polymer concentration in the effluent stream was detected by means of a differential refractometer (Waters Associates) as a function of eluate volume. The latter parameter was automatically indicated on the recorded chromatogram by means of a specially designed glass reservoir of constant volume, through which the effluent stream was passing. After each filling the reservoir was emptied through an automatically operated electrovalve and the corresponding signal transmitted to the recorder. The columns were kept at room temperature and the refractometer was operated at $35^{\circ} \mathrm{C}$. Flow rates were in the order of $1 \mathrm{~cm}^{3} / \mathrm{min}$. In Figure 2 the calibration curve obtained with the

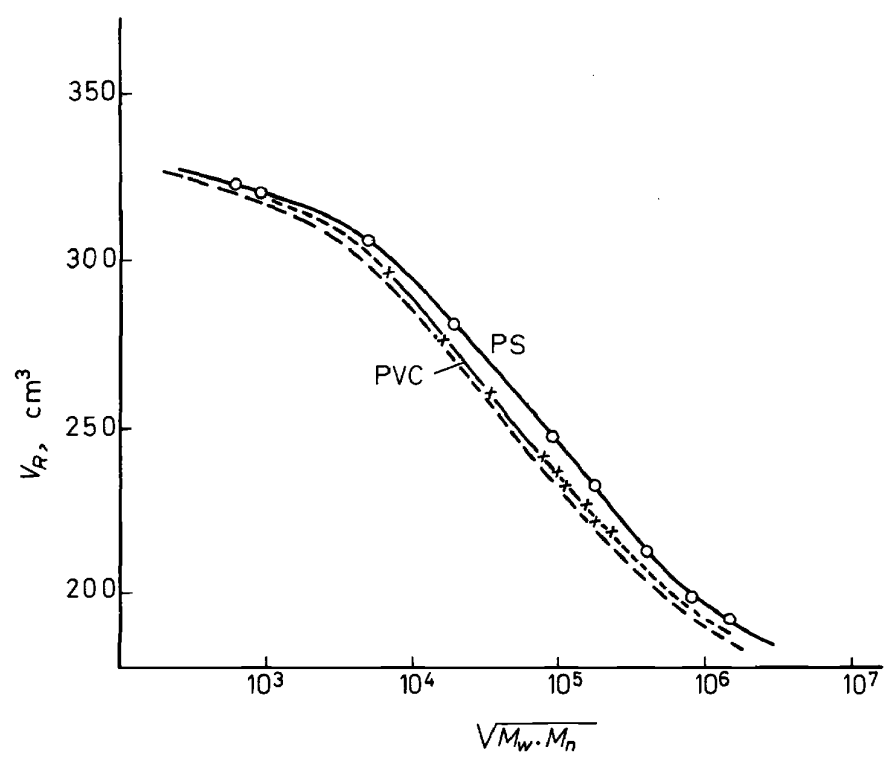

Figure 2. Exclusion chromatography, using THF as solvent. Calibration curves for polyvinyl chloride and polystyrene. Total column length: $8 \mathrm{~m}$. Packed with Spherosil beads. -....extrapolated by means of universal calibration principle ${ }^{19}$. - - - calibration based on maximum extended chain length ${ }^{56}$ 


\section{SOLUTION PROPERTIES OF POLYVINYL CHLORIDE}

aid of PVC fractions is compared with the calibration curve for polystyrene. PVC fractions, of weight-average molecular weight higher than 250000 , did not give reproducible chromatograms, and the calibration curve in the region of very high molecular weights was deduced from the polystyrene curve by application of the 'universal' calibration concept ${ }^{19}$, considering the effective hydrodynamic radius as the size parameter which determines the elution behaviour. The difficulty of obtaining reproducible chromatograms with PVC fractions of very high molecular weight may be ascribed to the formation of supermolecular aggregates during the elution at room temperature, the total time of elution being more than two hours. With PVC samples of lower molecular weight this phenomenon does not occur but, as in the case of light-scattering experiments, sufficient care should be taken in the preparation of the solutions in order to prevent the presence of aggregates, which, in extreme cases, may seriously distort the chromatogram and lead to erroneous results, as illustrated in Figure 3. Molecular

(a)

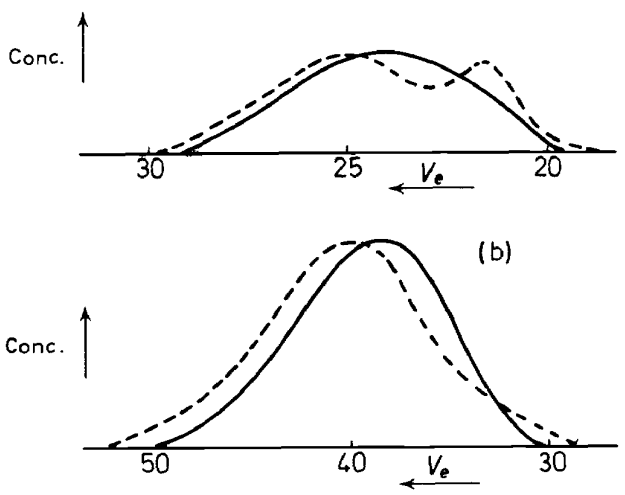

Figure 3. Distortion of chromatograms due to imperfect dissolution - - molecular solutions prepared by heating at $110^{\circ} \mathrm{C}$ - - - solutions containing aggregates. (a) PVC fraction with $\mathbf{M}_{w}=250000$. (b) Commercial PVC sample, polymerized in emulsion: $M_{n}=82000, M_{w}=$ 170000 .

weights were calculated from the chromatograms with the aid of the calibration curve using a computer programme. In the case of non-fractionated PVC samples the calculated values were not corrected for the finite resolving power of the chromatographic system. For fractionated samples this correction is not negligible and has to be applied in order to obtain significant values for the polydispersity. The correction procedure which we applied in this work, is based on Hamielec and Ray's analytical solution of the integral equation representing the chromatogram ${ }^{20,21}$. In the particular case of a Gaussian kernel function, which is a good approximation for our chromatographic system ${ }^{17}$ and a linear relationship between the elution volume and the logarithm of the molecular weight, throughout the region of interest for the polymer sample considered, the uncorrected ratio of weight-average 
to number-average molecular weight is related to the true ratio by means of Equation 3 :

$$
\left(\frac{M_{w}}{M_{n}}\right)_{\text {true }}=\left(\frac{M_{w}}{M_{n}}\right)_{\text {uncorr. }} \exp \left(-\sigma^{2} D^{2}\right)
$$

$\sigma^{2}$ is the variance of the Gaussian spreading function, supposed to be constant in the limited range of molecular weights present in the sample and $D$ is related to the slope of the calibration curve in the same range of molecular weights :

$$
D=-\frac{\mathrm{d} \ln M}{\mathrm{~d} \overline{V_{R}}}
$$

$V_{R}$ is the elution volume.

The variance of the characteristic spreading function in our chromatographic system was determined as a function of elution volume with the aid of a series of polystyrene calibration standards (manufactured by Pressure Chemical Company of Pittsburgh, $\mathrm{Pa}$.) with molecular weights ranging between 10000 and 1800000 . Variance values were calculated from Equation 3 by substitution of the measured $\left(M_{w} / M_{n}\right)_{\text {uncorr. }}$ and $D$ and by adopting the true $M_{w} / M_{n}$ values determined by Tung and Runyon ${ }^{22}$, with the aid of the 'reverse-flow'-technique (except for the highest molecular weight sample for which Tung and Runyon found a manifestly too high polydispersity; for the other samples the polydispersity values determined by Tung and Runyon are not very different from those indicated by the manufacturer and range between 1.02 and 1.08).

The adopted calibration procedure is based on the assumption that zone spreading is a unique function of elution volume for a given chromatographic system and independent of the nature of the solute. This assumption is experimentally verified ${ }^{22}$ and can be explained on the basis of the theory of chromatography ${ }^{23}$. In principle the same correction procedure may be applied in the case of polydispersed, unfractionated samples if proper account is taken of the variation of $\sigma^{2}$ and $D$ with elution volume ${ }^{21}$. However this does not seem worthwhile for the actual range of commercial PVC-resins whose polydispersities are confined between relatively close limits $\left(M_{w} / M_{n}=2.0 \pm 15 \%\right)$.

\section{Intrinsic viscosity determination}

The intrinsic viscosity, $[\eta]$ is the limit of the ratio $\left(\eta_{s}-\eta_{0}\right) / \eta_{0}$ for $c=0$ and $\dot{\gamma}=0$, where $\eta_{o}$ is viscosity of the solvent, $\eta_{s}$ is viscosity of the polymer solution, $c$ is concentration of the solution $\left(\mathrm{g} / \mathrm{cm}^{3}\right)$, and $\dot{\gamma}$ the average rate of shear during the measurement $\left(\mathrm{s}^{-1}\right)$. The ratio $\left(\eta_{s}-\eta_{o}\right) / \eta_{o}$ is called the specific viscosity $\left(\eta_{s p}\right)$.

The very definition of the intrinsic viscosity calls for an extrapolation formula leading from the actual measurements to a limiting value, if possible with the aid of a physical theory.

The solvents of PVC in this study, cyclohexanone and tetrahydrofuran (THF) are Newtonian liquids in the Ubbelohde viscometers used. To check that the solutions are also Newtonian the specific viscosity has been measured 
at the average shear rate of the ordinary Ubbelohde viscometer (mean height of fall $h=13 \mathrm{~cm}$, length of the capillary $=12 \mathrm{~cm}$ ) and at lower shear rates using a four-bulb Ubbelohde viscometer constructed according to Cragg and van Oene ${ }^{24}$. For the highest bulb the situation is that of an ordinary Ubbelohde viscometer. In order to avoid aggregates, all solutions in THF have been prepared as described in the section on light-scattering. The solutions in cyclohexanone have been prepared at $85^{\circ} \mathrm{C}$ under vigorous magnetic stirring No shear rate effects have been detected in dilute solutions of commercial PVC resins, but a slight effect was observed in hot $\left(70^{\circ} \mathrm{C}\right)$ cyclohexanone solutions of a high molecular weight experimental PVC, bulk-polymerized at $-15^{\circ} \mathrm{C},[\eta]_{\mathrm{cyclo}}=490 \mathrm{~cm}^{3} / \mathrm{g}$ Capillary diameter: 0.4 $\mathrm{mm}$, range of $\dot{\gamma}$ for the pure solvent: $200-50 \mathrm{~s}^{-1}$.

Analysis of the data revealed that in this particular case the value of $\eta_{s p}$ measured in an ordinary viscometer was between 3.6 and 4.5 per cent lower than the extrapolated value at zero rate of shear. This small effect may be due to the existence of extremely high molecular weight fractions or aggregates in the investigated solution. All solutions in THF investigated in this study have been considered to be Newtonian.

In order to extrapolate the measured $\eta_{s p}$ values to zero concentration. Schulz and Blaschke $\mathrm{e}^{25}$ have proposed an empirical equation which fits the behaviour of many dilute polymer solutions:

$$
\frac{\eta_{s p}}{c}=[\eta]\left(1+k_{S B} \eta_{s p}\right)
$$

Huggins $^{26}$ has theoretically derived the same formula, and proposed an expansion in a power series of $[\eta] . c, c$ being the intervening variable in most theoretical developments. Unfortunately the expression known in the literature as the Huggins's viscosity equation:

$$
\frac{\eta_{s p}}{c}=[\eta]_{H}\left(1+k_{H}[\eta]_{H} c\right)
$$

is only a restricted development of the original formula. The Kraemer equation, which is also frequently used can be written as follows:

$$
\frac{\ln \left(1+\eta_{s p}\right)}{c}=[\eta]_{K}\left(1+k_{K}[\eta]_{K} c\right)
$$

The two values $[\eta]_{H}$ and $[\eta]_{K}$ although considered identical are not, because the experimental values used to adjust the parameters $[\eta]$ and $k$ are not very small.

This subject has been discussed in detail by Elias ${ }^{27}$, Ibrahim ${ }^{28}$ and Berry ${ }^{29}$.

In the case of PVC solutions in THF, $[\eta]_{H}$ and $[\eta]_{K}$ are found nearly identical when $0.2<[\eta] c<1.5, k_{H}-k_{\mathrm{K}} \simeq 0.5$ as may be expected when $k_{H} \simeq 0.33$; but $[\eta]_{S B}$ remains higher than the other extrapolated values within the 0.95 confidence limits. The fit between the three equations is still poorer when the range of $\eta_{s p}$ values encompasses 0.2 to 2.5 . The least-square treatment of the experimental values shows that the Equation 5 fits a wider range of $\eta_{s p}$ values than Equations 6 and 7. Figure 4 shows the results of measurements on two PVC samples for a restricted range of $\eta_{s p}$ values (a) 


\section{A. J. DE VRIES, C. BONNEBAT AND M. CARREGA}

and for an extended one (b). The $\Delta$ values are the sums of squares of the differences between experimental and least-square lines ordinates. The much better fit of the 'Schulz-Blaschke-Huggins' equation is striking.

Schulz claimed that the $k_{S B}$ value does not vary appreciably with different polymer-solvent systems as has been well confirmed by our experience with

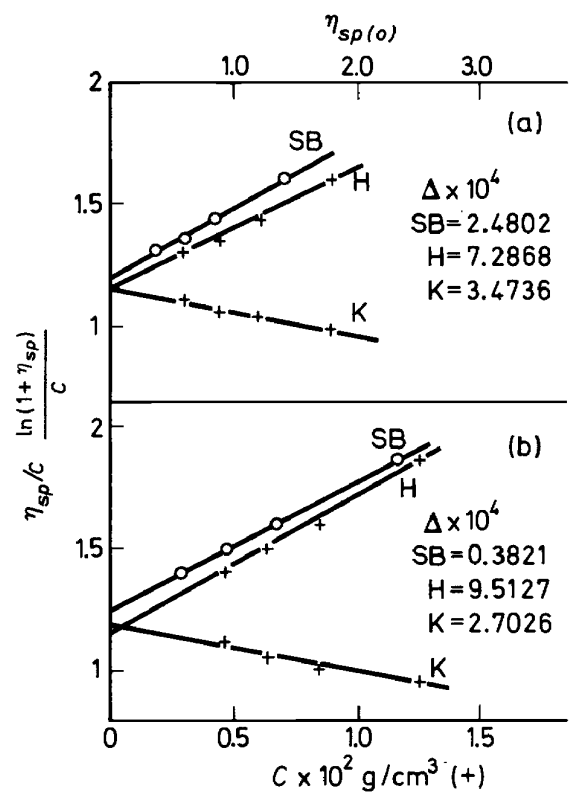

Figure 4. Intrinsic viscosity determination by three different methods. (a) restricted range of $\eta_{s p}$-values-Schulz-Blaschke: $[\eta]=1.191 \pm 0.05$; Huggins: $[\eta]=1.147 \pm 0.11$; Kraemer: $[\eta]=1.147 \pm 0.07$. (b) extended range of $\eta_{s p}$-values-Schulz-Blaschke: $[\eta \overline{]}]=1.251 \pm 0.01$;

Huggins: $[\eta]=1.158 \pm 0.13 ;$ Kraemer $:[\eta]=1.170 \pm 0.06$

$0.2<k_{S B}<0.3$. Moreover, when Equation 5 does not fit well the experimental results in the $0.2-1.5 \eta_{s p}$ range with $k_{S B}$ outside 0.2 to 0.3 , the reason has always been found to be an imperfect dissolution of the polymer. This is a good lead for the experimentalist.

Dividing the two members of Equations 5, 6 and 7 by the corresponding $[\eta]$ the following expressions are obtained:

$$
\begin{gathered}
\frac{\eta_{s p}}{c} \cdot[\eta]_{S B}^{-1}=1+k_{S B} \eta_{s p} \\
\frac{\eta_{s p}}{c} \cdot[\eta]_{H}^{-1}=1+k_{H}[\eta]_{H} c \\
\frac{\ln \left(\eta_{s p}+1\right)}{c}[\eta]_{K}^{-1}=1+k_{K}[\eta]_{K} c .
\end{gathered}
$$

Plotting $\eta_{s p} / c .[\eta]^{-1}$ vs. $\eta_{s p}$ (or $\left.[\eta] c\right)$ for each series of experimental data, gives straight lines, the slopes of which are the ' $k$ ' values; each line must 
intersect the ordinate axis at 1 . The results of least-square treatments for 24 experimental values (6 PVC samples at 4 concentrations in THF at $25^{\circ} \mathrm{C}$ ) are the following ( 95 per cent confidence limits):

$$
\begin{aligned}
k_{S B} & =0.228( \pm 0.064) \text { with intercept } 1.030( \pm 0.074) \\
k_{H} & =0.409( \pm 0.150) \text { with intercept } 1.045( \pm 0.119) \\
k_{K} & =-0.121( \pm 0.017) \text { with intercept } 0.995( \pm 0.014) \\
k_{H} & -k_{K}=0.530( \pm 0.15)
\end{aligned}
$$

In the same manner $k_{S B}$ (cyclohexanone at $25^{\circ} \mathrm{C}$ ) was found to be 0.26 . The kinetic energy correction cannot be neglected in the case of PVC solutions in THF, even with a capillary of diameter equal to $0.3 \mathrm{~mm}$, the error on [ $\eta]$ being of the order of 1 per cent; with a $0.5 \mathrm{~mm}$ capillary it amounts to 10 per cent, in contrast with $\mathrm{PVC}$ solutions in cyclohexanone at $25^{\circ} \mathrm{C}$ where the error is inferior to 1 per cent.

\section{RESULTS AND DISCUSSION}

\section{Intrinsic viscosity and unperturbed dimensions}

The intrinsic viscosity in THF has been plotted in Figure 5 as a function of weight-average molecular weight for 25 fractions in a range of $M_{w}$ values

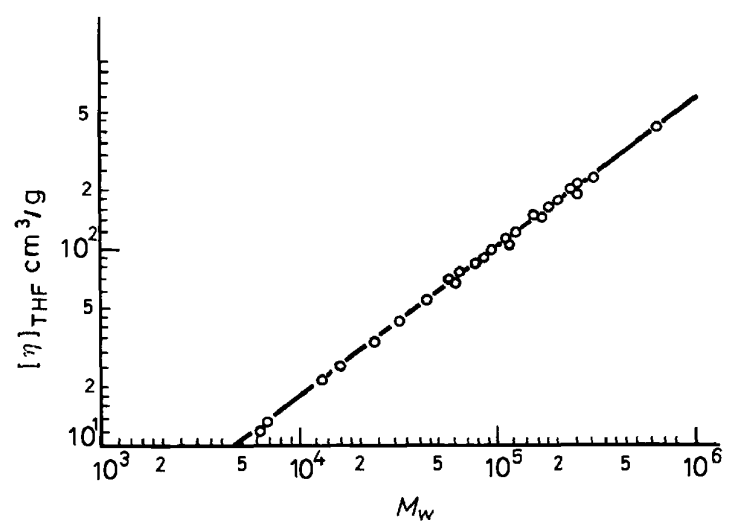

Figure 5. Empirical relationship between intrinsic viscosity in THF and weight-average molecular weight for 25 PVC fractions (Equation 8).

between 6400 and 650000 . The results can be represented by the empirical relationship:

$$
[\eta]_{\mathrm{THF}}^{25^{\circ} \mathrm{C}}=1.63 \times 10^{-2} M_{w}{ }^{0} \cdot{ }^{760} \cdot\left(\mathrm{cm}^{3} / \mathrm{g}\right)
$$

Equation 8 has been derived by means of a linear regression analysis which takes account of the fact that both variables are experimentally determined quantities and, consequently, subject to error. This so-called 'least-area' method consists in minimizing $\Sigma \Delta y \Delta x$, where $\Delta y$ and $\Delta x$ are the deviations of the observed values of the two variables $y$ and $x$ with respect to the fitted 
straight line ${ }^{30}$. In the case of Equation $8, y=\log [\eta]$ and $x=\log M_{w}$ The standard error of estimate is defined by:

$$
s=\sqrt{\frac{\Sigma \Delta y \Delta x}{N-2}}
$$

where $N$ is the number of samples investigated $(N=25)$. This regression analysis has been systematically applied to all empirical relationships discussed in the present paper. The $s$-value calculated from the data in Figure 5, is equal to 0.007 which means that Equation 8 may be written as follows :

$$
[\eta]_{\mathrm{THF}}^{25^{\circ} \mathrm{C}}=1.63 \times 10^{-2} M_{w}^{0.760} \times 1.017
$$

The estimated average error is, therefore, in the order of 2 per cent. The more usual least-squares fit yields the following result for the exponent: $v=0.760 \pm 0.007$. The relatively high value of the Mark-HouwinkSakadura exponent reflects the excellent solvent power of THF and the non-negligible expansion of the dissolved PVC molecules with respect to their unperturbed dimensions. Equation 8 is very similar to comparable relationships reported in the literature for $\mathrm{PVC}$ fractions in a narrower range of molecular weights. Bohdanecký $e t a l^{2}$ found the following relationship:

$$
[\eta]_{\mathrm{THF}}^{25^{\circ} \mathrm{C}}=1.50 \times 10^{-2} M_{w}^{0.77}
$$

in a range of $M_{w}$ values between 10000 and 300000 . An empirical relationship, which is in still better agreement with our Equation 8 , is the one derived by Freeman and Manning ${ }^{31}$ in a range of molecular weights comparable to the range explored by Bohdanecký et al. :

$$
[\eta]_{\mathrm{THF}}^{25^{\circ} \mathrm{C}}=1.63 \times 10^{-2} M_{w}^{0.766}
$$

Freeman and Manning observed systematic deviations and abnormally dispersed values in the range of very high molecular weights which may be explained by the presence of supermolecular aggregates resulting in overestimated values for $M_{w}$ determined by light-scattering Another explanation, suggested by the authors themselves ${ }^{31}$, based on the supposed occurrence of long-chain branching, was not confirmed by the present study, as will be further discussed below. It is well-known that the relationship between intrinsic viscosity and weight-average molecular weight depends on the polydispersity of the polymer samples. The effect of polydispersity will be discussed in some detail in a later section of this paper; it may be noted here, however, that the slight variations in polydispersity of the investigated fractions (see Table I) should not affect the relationship represented by Equation 8. Even in the case of absolute monodisperse fractions the intrinsic viscosity values would have been less than 2 per cent higher than those given by Equation 8, which is not significantly different from the estimated experimental error.

According to the current theories of dilute polymer solutions ${ }^{32,33}$ the intrinsic viscosity may be expressed by Equation 11 :

$$
[\eta]=\Phi\left(\frac{\bar{R}^{2}}{M}\right)^{\frac{3}{2}} M^{\frac{1}{2}}
$$




\section{SOLUTION PROPERTIES OF POLYVINYL CHLORIDE}

$\bar{R}^{2}$ is the mean square end-to-end distance of the polymer chain, and $\Phi$ is the so-called Flory constant. A theory of Ptitsyn and Ejzner ${ }^{34}$ leads to the conclusion that $\Phi$ depends on the expansion of the polymer coil; assuming that the effect of solvent on the average coil dimensions may be expressed by Equation 12:

$$
\bar{R}^{2}=\text { constant } \times M^{1+\varepsilon}
$$

the latter authors derived Equation 13 for the solvent dependence of $\Phi$ :

$$
\Phi(\varepsilon)=\Phi_{0}\left(1-2.63 \varepsilon+2.86 \varepsilon^{2}\right) \text {. }
$$

Under theta-conditions, $\varepsilon=0, \Phi=\Phi_{0}$ and Equation (11) may be written as follows :

$$
\begin{aligned}
& {[\eta]_{\theta}=\Phi_{0}\left(\frac{\bar{R}_{0}^{2}}{M}\right)^{\frac{3}{2}} M^{\frac{1}{2}} ;} \\
& {[\eta]_{\theta}=K_{\theta} M^{\frac{1}{2}} .}
\end{aligned}
$$

The ratio $\bar{R}_{0}^{2} / M$, characteristic of the unperturbed dimensions of the dissolved macromolecule, depends mainly on the length and angle of the valence bonds in the polymer chain, as well as on hindrance to internal rotations ${ }^{35,36}$. Another related characteristic ratio, often discussed in the literature, is $\bar{R}_{0}^{2} / n l^{2}$, where $n$ is the number of bonds in the main chain and $l$ the bond length. The latter ratio is equal to 1 for an ideal long chain molecule, obeying random-flight statistics.

Several authors have considered the problem of obtaining information on the unperturbed dimensions from intrinsic viscosity-molecular weight relationships, observed in good solvents. This is only possible, obviously, if a reasonable estimate can be made of the solvent- and molecular weightdependent 'viscosity expansion factor', defined by:

$$
\alpha_{\eta}^{3}=[\eta] /[\eta]_{\theta}
$$

The expansion factor depends on the thermodynamic properties of the polymer solution and is most frequently expressed in terms of the parameter $z$ defined ${ }^{37}$ by Equation 17:

$$
z=\left(\frac{3}{2} \pi\right)^{\frac{3}{2}}\left(\bar{R}_{0}^{2} / M\right)^{-\frac{3}{2}} B M^{\frac{1}{2}}
$$

where $B$ is related to Flory's interaction parameter, $\chi_{1}$, by :

$$
B=\bar{v}^{2}\left(1-2 \chi_{1}\right) / V_{1} N_{A}
$$

$\bar{v}$ is the partial specific volume of the polymer, $V_{1}$ the molar volume of the solvent and $N_{A}$ Avogadro's number. Based on Flory's assumption that the expansion of the effective hydrodynamic radius is identical with that of the radius of gyration, Flory and Fox ${ }^{38}$ applied the well-known Flory's equation 19 in combination with Equations 15 and 16 in order to derive Equation 20:

$$
\begin{gathered}
\alpha^{5}-\alpha^{3}=C_{M}\left(1-2 \chi_{1}\right) M^{\frac{1}{2}} \\
{[\eta]^{3} / M^{\frac{1}{3}}=K_{\theta}^{\frac{2}{\theta}}+C_{M}\left(1-2 \chi_{1}\right) K_{\theta}^{\frac{4}{4}} M /[\eta] .}
\end{gathered}
$$




\section{A. J. DE VRIES, C. BONNEBAT AND M. CARREGA}

The extrapolation procedure based on Equation 20 and known as the Flory-Fox-Schaefgen method usually yields under-estimated values for $\boldsymbol{K}_{\boldsymbol{\theta}}$ if applied to intrinsic viscosity measurements obtained in good solvents ${ }^{39}$. Our experimental results are plotted in Figure 6; the linear relationship

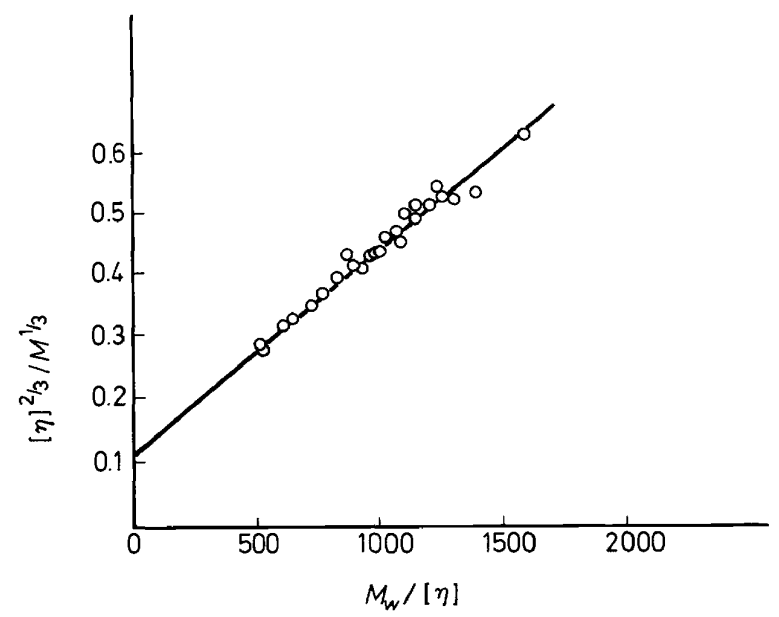

Figure 6. Determination of $K_{\theta}$ according to Flory-Fox-Schaefgen (Equation 20).

predicted by Equation 20 is fairly well confirmed and would lead to an estimated value for $K_{\theta}=0.043$. Taking account of the fact that the effective hydrodynamic radius increases less rapidly with solvent power than the radius of gyration, and assuming that this effect is adequately represented by the Ptitsyn-Ejzner theory, the relationship between the two expansion factors may be written as follows:

$$
\alpha_{\eta}^{3}=\frac{\Phi(\varepsilon)}{\Phi_{0}} \alpha^{3}
$$

For the PVC-THF system, $\varepsilon=0.173$, as follows from Equations 8,11 and 12; substitution of this value into Equation 13 leads to the following result:

$$
\frac{\Phi(\varepsilon)}{\Phi_{0}}=0.625
$$

If this correction is applied to the Flory-Fox-Schaefgen analysis of our data, an extrapolated value of $K_{\theta}=0.069$ is found which is still considerably lower than the values obtained by other extrapolation procedures which will be discussed now.

Based on a new expression for the excluded volume effect derived by Kurata, Stockmayer and Roig ${ }^{40}$, the two first-mentioned authors have proposed an extrapolation method which they were able to apply success- 


\section{SOLUTION PROPERTIES OF POLYVINYL CHLORIDE}

fully to a great number of experimental data ${ }^{39}$. This method makes use of the following equations:

$$
\begin{gathered}
\alpha_{\eta}^{3}-\alpha_{\eta}=1.10 g\left(\alpha_{\eta}\right) z \\
g\left(\alpha_{\eta}\right)=8 \alpha_{\eta}^{3} /\left(3 \alpha_{\eta}^{2}+1\right)^{\frac{3}{2}} ; \\
{[\eta]^{\frac{2}{3}} / M^{\frac{1}{3}}=K_{\frac{z}{g}}^{\frac{2}{2}}+0.363 \Phi_{0} B\left[g\left(\alpha_{\eta}\right) M^{\frac{3}{3}} /[\eta]^{\frac{1}{3}}\right]}
\end{gathered}
$$

The value of $\Phi_{0}$ is equal to $2.87 \times 10^{23} \mathrm{c.g}$.s. for a homogeneous polymer. In the analysis of the experimental data according to Equation 25, the value of $g\left(\alpha_{\eta}\right)$ is first assumed equal to one, in order to obtain an approximate value of $K_{\theta}$ which then permits an evaluation of $[\eta]_{\theta}, \alpha_{\eta}$ and $g\left(\alpha_{\eta}\right)$ with the aid of Equations 15, 16 and 24. Using this result, the data are replotted according to Equation 25. Because of the rapid convergence of this procedure further adjustment of the function $g\left(\alpha_{\eta}\right)$ does not change significantly the extrapolated value of $K_{\theta}$.

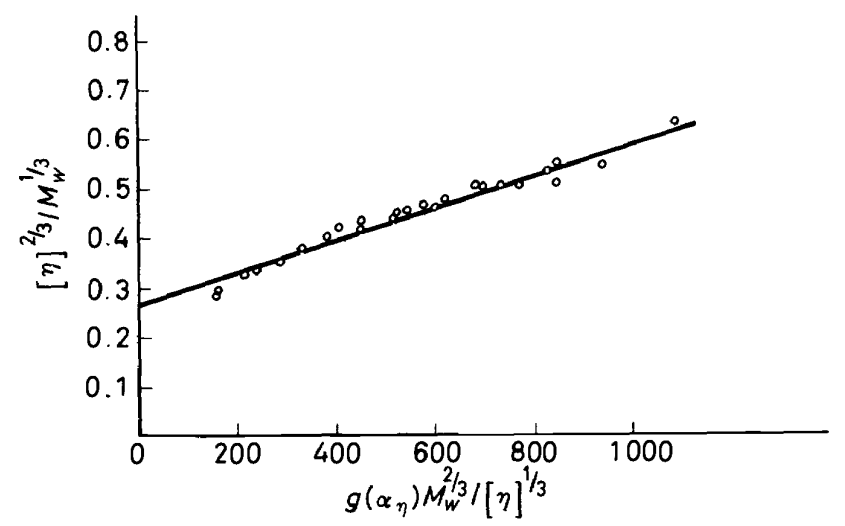

Figure 7. Determination of $K_{\theta}$ according to Kurata-Stockmayer (Equation 25).

The application of this method is illustrated in Figure 7 and yields the following expression:

$$
[\eta]^{\frac{2}{3}} / \boldsymbol{M}_{w}^{\frac{1}{3}}=0.265+0.32310^{-3}\left[g\left(\alpha_{\eta}\right) M_{w}^{\frac{2}{3}} /[\eta]^{\frac{1}{3}}\right] ; s=0.023 .
$$

The extrapolated value for $K_{\theta}$ is equal to 0.137 c.g.s. From the slope of the straight line in Figure 7 and by application of Equation 25 it might also be deduced that :

$$
B \Phi_{0}=0.88 \times 10^{-3}
$$

which would yield for $B$ a value in the order of $3 \times 10^{-27} \mathrm{c}$.g.s. The estimated value for $K_{\theta}$ seems reasonable and is somewhat lower than the only value reported in the literature, which is claimed to have been obtained under theta-conditions, namely $K_{\theta}=0.156$ in benzyl alcohol at $155.4^{\circ} \mathrm{C}$ by Sato et $a l^{41}$ The calculated value for $B$, however, is considerably lower than the 


\section{A. J. DE VRIES, C. BONNEBAT AND M. CARREGA}

one obtained from the second virial coefficient measurements as will be shown below.

More recently it was suggested by Stockmayer and Fixman ${ }^{42}$ that a very simple extrapolation procedure might be used, based on an approximate result derived by Kurata and Yamakawa ${ }^{43}$ :

$$
\alpha_{\eta}^{3}=1+1.55 z
$$

which would lead to the following extrapolation formula:

$$
[\eta] / M^{\frac{1}{2}}=K_{\theta}+0.51 B \Phi_{0} M^{\frac{1}{2}}
$$

It had already been shown earlier, however, by Burchard ${ }^{44}$ that Equation 28 does not represent, in general, an adequate description of the experimental data obtained in good solvents. This is clearly illustrated by Figure 8; the

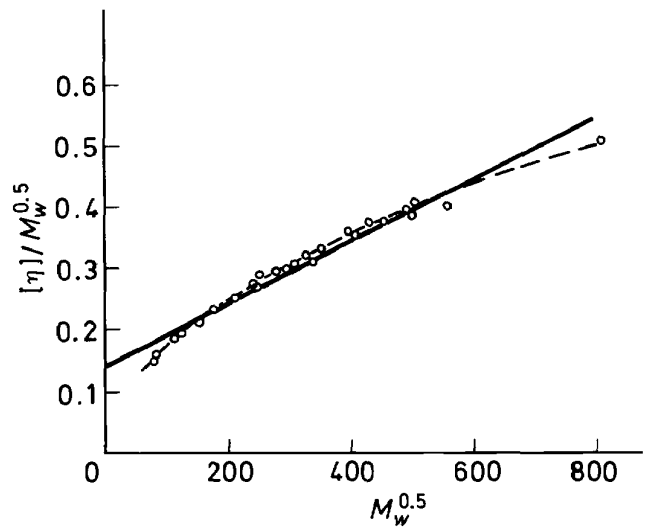

Figure 8. Determination of $K_{\theta}$ according to Stockmayer-Fixman. --- Equation (8).

Equation (29),

curve drawn in this figure was calculated from the empirical intrinsic viscosity-molecular weight relationship, Equation 8, and offers, as might be expected, an accurate description of the experimental results. If, nevertheless, we try to construct a straight line through the experimental points in accordance with Equation 28, the regression analysis yields a result very similar to the one obtained with the more rigorous extrapolation formula 25 :

$$
[\eta] / M_{w}^{\frac{1}{2}}=0.139+0.510^{-3} M_{w}^{\frac{1}{2}} ; s=0.016 .
$$

Both the values of $K_{\theta}$ and $B$, obtained by comparing Equations 28 and 29 are nearly identical with those derived from Equation 26 . It is, however, obvious that quite different results would have been obtained if Equation 28 were applied in a limited range of experimental data, as suggested by several authors $29,45,46$. 


\section{SOLUTION PROPERTIES OF POLYVINYL CHLORIDE}

In $1955 \mathrm{Krigbaum}^{4 /}$ proposed an extrapolation procedure making use of measured values of the second virial coefficient. According to the theory of $\mathrm{Zimm}^{48}$ the second virial coefficient is given by:

$$
A_{2}=\frac{1}{2} N_{A} B h(z) \text {. }
$$

The function $h(z)$, whose maximum value is equal to one, decreases slowly with increasing values of $z$ and reflects, therefore, the well-established although slight molecular weight dependence of $A_{2}$. Krigbaum, however, neglected this molecular weight effect and assumed $h(z)$ equal to one; adopting further a linear relationship between $\alpha^{3}$ and $z$, comparable to Equation 27, he derived the following expression:

$$
[\eta] / M_{w}^{\frac{1}{2}}=K_{\theta}+1.263 \frac{\Phi_{0}}{N_{A}} A_{2} M_{\omega}^{\frac{1}{2}} .
$$

This equation is, in principle, identical with Equation 28, except for a small numerical difference in the coefficient of the second term. In reality, however, the use of Equation 31 with experimentally determined values of $A_{2}$, leads to different results because of the molecular weight dependence of the second virial coefficient. This is illustrated by Figure 9 where the experimental data

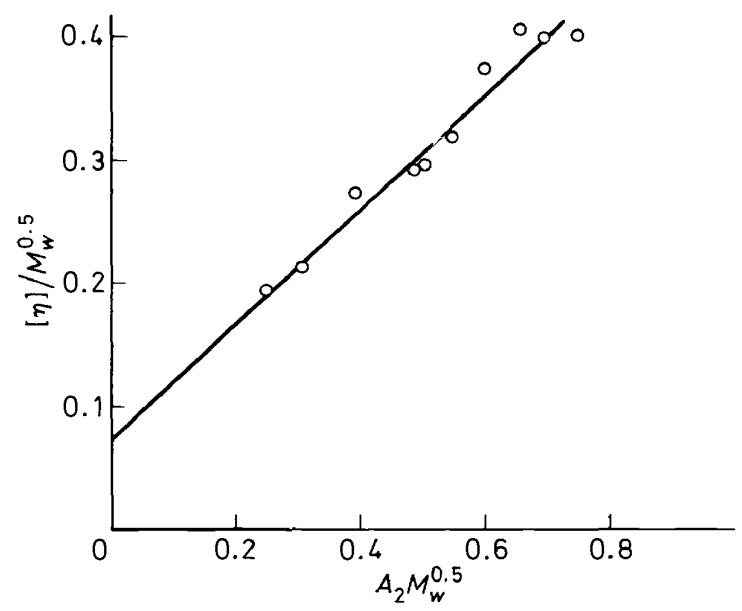

Figure 9. Determination of $K_{\theta}$ according to Krigbaum (Equation 31).

for 10 PVC fractions with $M_{w}$ values, in a range between 16000 and 310000 , are plotted in accordance with Equation 31. The experimental scatter does not allow a good correlation; the data may, nevertheless, be represented by Equation 32

$$
\begin{gathered}
{[\eta] / M_{w}^{\frac{1}{2}}=0.073+0.47 A_{2} M_{w}^{\frac{1}{2}} ; s=0.0175 .} \\
225
\end{gathered}
$$


A. J. DE VRIES, C. BONNEBAT AND M. CARREGA

The experimental scatter can be reduced if we introduce an approximate expression for the second virial coefficient proposed by Bohdanecky ${ }^{49}$ on the basis of the modified Flory-Orofino theory ${ }^{50}$ :

$$
A_{2}=1.52 \frac{K_{\theta}}{M^{\frac{1}{2}}} z^{0.7}
$$

Equation 33 is in good agreement with the experimentally observed molecular weight dependence of the second virial coefficient (Figure 11) and may be combined with Equations 14, 15, 17 and 31 in order to give a new relationship :

$$
[\eta] / M_{w}^{\frac{1}{2}}=K_{\theta}+C_{B} M_{w}^{0.35}
$$

where

$$
C_{B}=\frac{0.88}{N_{A}} K_{\theta}^{0.3} \Phi_{0}^{1.7} B^{0.7}
$$

Analysis of the data on all 25 fractions, in accordance with Equation 34, is illustrated by Figure 10 and leads to the following empirical relationship:

$$
[\eta] / M_{w}^{\frac{1}{2}}=0.074+0.4110^{-2} M_{w}^{0.35} ; s=0.0099 .
$$

The extrapolated intercept is in good agreement with the one obtained by application of Equation 32 but does not seem to allow a reasonable estimate of $K_{\theta}$, without further corrections. Cowie ${ }^{45}$ suggested that the intercept multiplied by the factor $\Phi_{\theta} / \Phi(\varepsilon)$ might be identical with $K_{\theta}$ and gave some experimental evidence in favour of this suggestion. Such an empirical procedure does not appear justified, however, by any theoretical analysis, even approximate and comparable to the one leading to the Kurata-Stockmayer relationship, Equation 25. Nevertheless, if we follow Cowie's suggestion Equations 32 or 35 would yield a $K_{\theta}$ value equal to 0.118 , which is somewhat lower than the values given by Equations 26 and 29. Although the exponent 0.35 gives a somewhat better representation of the experimental data than the exponent 0.5 , Equation 35 should only be considered as an empirical adjustment, as clearly illustrated by Figure 10 and its use for the determination of $K_{\theta}$ is, therefore, subject to serious doubts.

If we accept a value of 0.14 for $K_{\theta}$, the following values for the characteristic ratios are obtained:

$$
\begin{aligned}
& \frac{\bar{R}_{0}^{2}}{M}=\left(\frac{K_{\theta}}{\Phi_{0}}\right)^{\frac{2}{3}}=0.6210^{-16}\left(\mathrm{~cm}^{2}\right) \\
& \frac{\bar{R}_{0}^{2}}{n l^{2}}=\frac{M_{0}}{2 l^{2}}\left(\frac{K_{\theta}}{\Phi_{0}}\right)^{\frac{2}{3}}=8.17
\end{aligned}
$$

where $\Phi_{0}=2.87 \times 10^{23} ; M_{0}=62.5$ and $l=1.54 \times 10^{-8} \mathrm{~cm}$

Finally, accepting a value of $109.5^{\circ}$ for the valence bond angle, the ratio $\sigma$, 


\section{SOLUTION PROPERTIES OF POLYVINYL CHLORIDE}

characteristic of the hindrance to internal rotation about the single bonds of the chain ${ }^{33}$, would be equal to:

$$
\sigma=\left(\bar{R}_{0}^{2} / \bar{R}_{0, f}^{2}\right)^{\frac{1}{2}}=2.02
$$

The values for these characteristic ratios are of the same order of magnitude as those reported for other vinyl polymers ${ }^{36,39}$, but will of course, vary as a function of the accepted value for $K_{\theta}$. The value of 0.156 , for instance, reported by Sato et al. $^{41}$ to have been obtained under theta-conditions would yield slightly higher values for the characteristic ratios. It is also obvious that the

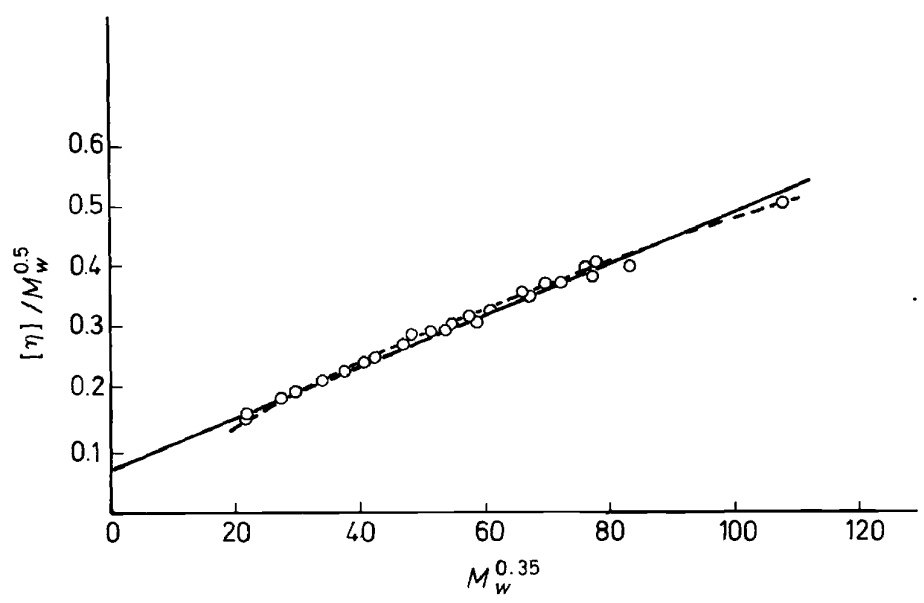

Figure 10. Determination of $K_{\theta}$ according to Bohdanecký. Equation (8).

extrapolated intercept in Figure 7, for instance, is rather strongly dependent on the range of molecular weights for which Equation 25 is assumed to be valid. In the absence of any objective criteria concerning the range of validity for the several extrapolation formulae, we have preferred, in this paper, to include all the experimental data instead of trying to define restricted ranges of validity for the different equations. In view of the uncertainty concerning the absolute values of the characteristic ratios, any detailed discussion of their possible dependence on the nature of the solvent ${ }^{46}$ appears to us untimely. A more limited investigation of the intrinsic viscosity in cyclohexanone as a function of molecular weight yielded results which were significantly different from those obtained with THF. The extrapolated $K_{\theta}$ values were systematically higher than those reported above, but, for the moment, it seems impossible to decide if this is due to a real solvent effect or to the possible presence of aggregates in the cyclohexanone solutions of the higher molecular weight fractions. The intrinsic viscosity-molecular weight relationship in cyclohexanone was found to be:

$$
[\eta]_{\text {cyclo. }}^{25^{\circ} \mathrm{C}}=2.57 \times 10^{-2} M_{w}^{0.725} \times 1.02
$$




\section{A. J. DE VRIES, C. BONNEBAT AND M. CARREGA}

\section{Second virial coefficient and polymer-solvent interaction}

The second virial coefficients determined by light-scattering for 10 PVC fractions, dissolved in THF, are plotted on a double logarithmic scale as a function of weight-average molecular weight in Figure 11. The second virial coefficient is only slowly varying with increasing molecular weight according to the relationship:

$$
A_{2}=8.510^{-3} M_{w}^{-0.146} \times 1.10
$$

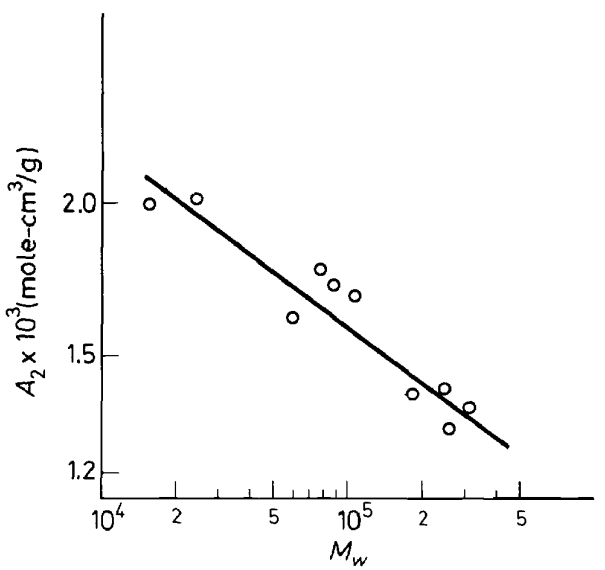

Figure 11. Molecular weight dependence of second virial coefficient. Double logarithmic plot (Equation 40).

The molecular weight dependence is in good agreement with the relationship proposed by Bohdanecký, Equation 33, which after substitution of Equation 17 may be written as follows:

$$
A_{2}=0.7 K_{\theta}^{0,3}\left(B \Phi_{0}\right)^{0.7} M^{-0.15} \text {. }
$$

With $K_{\theta}=0.14$ and $\Phi_{\theta}=2.87 \times 10^{23}$, comparison of Equations 40 and 41 will yield a value for $B$, equal to $1.5 \times 10^{-26}$ which is considerably larger than the value calculated from the intrinsic viscosity data by means of the Kurata-Stockmayer relationship, Equation 25. Bohdanecký has recently ${ }^{7}$ reported $B$ values of the same order of magnitude, derived from intrinsic viscosity data, with the aid of an empirical relationship proposed by Berry $^{29}$ for the polystyrene-toluene system:

$$
\left(\alpha_{\eta}^{3}\right)^{\frac{1}{2}}=1+0.42 z / \alpha_{n}^{3} .
$$

On the other hand, Schulz and Bauman ${ }^{51}$ have published the results of a detailed study on the polystyrene-THF system from which they derived a value of $0.69 \times 10^{-26}$ which is about twice as low as our calculated value for the PVC-THF system.

The relatively high value for $B$ seems to indicate a very strong polymersolvent interaction; if this value is substituted into Equation 18 together 
with the appropriate values for $\bar{v}$ and $V_{1}$, the calculated value for $\chi_{1}$ becomes negative, as had already been noted by Bohdaneck-y $\dot{y}^{7}$. Taking $\bar{v}=0.7429$, according to Kegeles et al. ${ }^{52}$ and $V_{1}=72.1 / 0.8811=81.8 \mathrm{~cm}^{3}$, the value of $\chi_{1}$, calculated from Equation 18 becomes:

$$
\chi_{1}=-0.168 \text {. }
$$

Bohdanecký ${ }^{7}$, who calculates still lower values for $\chi_{1}$, for a large number of various PVC-solvent systems, attributes the differences between these results and those reported in the earlier literature to the influence of aggregation, the effect of concentration and the neglect of the molecular weight dependence of $A_{2}$. In Figure 12 we have plotted the dimensionless ratio $A_{2} M_{w} /[\eta]$ as a

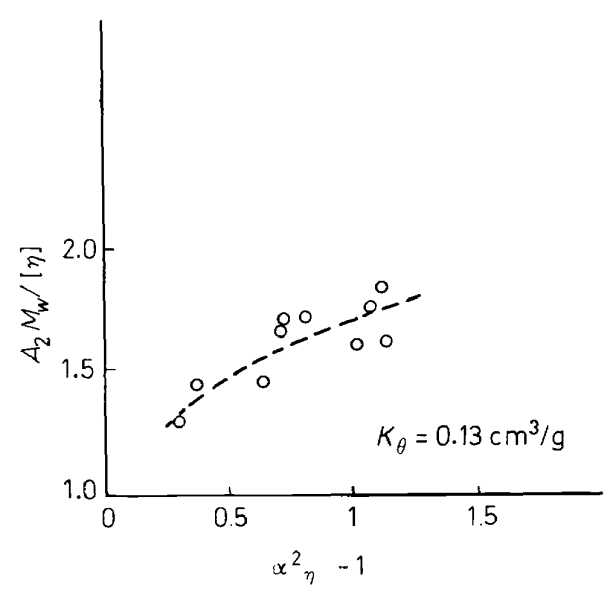

Figure 12. Dimensionless ratio $A_{2} M_{w} /[\eta]_{\mathrm{THF}}$ as a function of $\alpha_{\eta}^{2}-1$, for $K_{\theta}=0.13$.

function of $\alpha_{\eta}^{2}-1$. Its value varies between 1.3 and 1.8 , which is of the same order of magnitude as the values reported for other polymer-solvent systems ${ }^{39}$, but appreciably higher than those predicted by various theoretical treatments ${ }^{53}$. The discrepancy between theory and experiment would be reduced if we admit a much lower value for $K_{\theta}$ which does not appear justified by the existing experimental data on the intrinsic viscosity-molecular weight relationship. Experimental errors in $A_{2}$ are relatively important but, according to our experience, the use of light-scattering in the case of PVC solutions more often leads to an under-estimation of $A_{2}$ because of the presence of aggregates and does not seem to offer, therefore, a plausible explanation of the relatively high values observed. It may also be assumed that the effect of polydispersity on the measured $A_{2}$-values is negligible ${ }^{54}$. Finally we note that our results are in fair agreement with the $A_{2}$-values determined by either light-scattering or osmotic pressure measurements, reported by Bohdanecký et al. ${ }^{2}$ although the latter authors found a slightly larger molecular weight-dependence. 


\section{Molecular characterization of polydisperse PVC-samples}

The range of average molecular weights encountered in commercial PVC resins is actually very restricted and encompasses $M_{w}$ values between about 50000 and 180000 . The number-average molecular weights $M_{n}$ are in general about twice as low as the weight-average molecular weights and the molecular weight distribution (MWD) is rather close to the so-called 'most probable' distribution. More generally speaking, the familiar exponential function, due to $\mathrm{Schulz}^{55}$, given by Equation 43 may be considered as a satisfactory approximation to the MWD observed in commercial PVC samples.

$$
w(M)=\left[y^{h+1} / \Gamma(h+1)\right] M^{h} \exp (-y M)
$$

where

$$
y=h / M_{n}=(h+1) / M_{w}=(h+2) / M_{z}
$$

Observed $M_{w} / M_{n}$-values being, in general, close to 2 , the value of the parameter $h$ should not be far from unity. The $M_{z}$-values calculated from Equation 44 are often smaller than the ones derived from the observed MWD, but it should be kept in mind that the experimental error in $M_{z}$ is relatively important if the MWD is determined by exclusion chromatography. In order to obtain reliable values for $M_{z}$ by means of the latter method, the calibration curve in the region of high molecular weights should be known with sufficient accuracy which, unfortunately, is not the case. In Figure 2 we have compared the calibration curve of our chromatographic system, obtained with PVC fractions of weight-average molecular weights between 6800 and 250000 , with a similar curve determined with polystyrene calibration standards in a wider range of molecular weights.

The calibration curve for PVC in the region of molecular weights larger than 250000 cannot be determined directly because of the aggregation phenomenon in the THF solutions, at room temperature (Figure 3). This part of the calibration curve (as well as the part referring to the very low molecular weight region) has been deduced from the polystyrene curve by application of the universal calibration principle ${ }^{19}$, considering the effective hydrodynamic radius as the relevant size parameter. Although the approximate validity of the latter procedure has been well established in the region of intermediate molecular weights, its extension into the region of extremely high or low molecular weights may introduce an error whose importance is actually unknown. We have also drawn in Figure 2 the calibration curve which should prevail if we accept the maximum extended chain length as a universal size parameter ${ }^{56}$. It is well known, now, that the latter procedure may lead to serious errors; in the particular case of PVC the use of this calibration method would result in underestimated absolute values for the molecular weight averages but would not affect appreciably the calculated polydispersity. This relatively favourable situation may be explained by the only slight difference in solvent power of THF between PVC and polystyrene. If, indeed, the effective hydrodynamic radius is considered as the relevant size parameter, the slope of the calibration curve as a function of $\log M$ may be written: 


$$
\frac{\mathrm{d} V_{R}}{\mathrm{~d} \log M}=\frac{\mathrm{d} \log R_{h}}{\mathrm{~d} \log M} \cdot \frac{\mathrm{d} V_{R}}{\mathrm{~d} \log R_{h}}=\frac{v+1}{3} \frac{\mathrm{d} V_{R}}{\mathrm{~d} \log R_{h}} .
$$

where $v$ is the exponent in the Mark-Houwink-Sakurada relationship and $R_{h}$ the effective hydrodynamic radius defined by:

$$
R_{h}=\left(\frac{0.3}{\pi N_{A}}[\eta] M\right)^{\frac{1}{3}}
$$

Taking $v=0.760$ for the PVC/THF system and equal to 0.725 for polystyrene $/ \mathrm{THF}^{57}$, the slopes of the two calibration curves would only differ, at any point, by a factor of $1.760 / 1.725=1.02$, which is within the limits of experimental error. The two calibration curves may be considered, consequently, as parallel, but the absolute value of the distance between the two curves is smaller than the one calculated by means of the extended chain length calibration.

The calculation of $M_{z}$ and higher molecular weight-averages from the chromatogram will not only be seriously affected by the uncertainty concerning the calibration curve but also by the finite resolving power of the chromatographic column. The latter factor is also responsible for the overestimated value of the polydispersity, expressed by the ratio $M_{w} / M_{n}$ calculated from the observed chromatogram. As we have already shown in

Table 2. Apparent and true polydispersity of PVC fractions

\begin{tabular}{rccccc}
\hline \multicolumn{1}{c}{$M_{w}$} & $\begin{array}{c}M_{w} / M_{n} \\
\text { uncorrected }\end{array}$ & $\begin{array}{c}\sigma^{2} \\
\left(\mathrm{~cm}^{6}\right)\end{array}$ & $\begin{array}{c}-D \\
\left(\mathrm{~cm}^{-3}\right)\end{array}$ & $\begin{array}{c}M_{w} / M_{n} \\
\text { true }\end{array}$ & $\begin{array}{c}\left(M_{w} / M_{n}\right)_{\text {true }} \\
\left(M_{w} / M_{n}\right)_{\text {uncorr. }}\end{array}$ \\
\hline 6800 & 1.23 & 27.46 & 0.052 & 1.14 & 0.927 \\
32000 & 1.30 & 55.45 & 0.043 & 1.17 & 0.900 \\
88000 & 1.38 & 62.91 & 0.044 & 1.22 & 0.884 \\
107000 & 1.37 & 66.38 & 0.044 & 1.20 & 0.878 \\
125000 & 1.55 & 71.71 & 0.047 & 1.32 & 0.851 \\
165000 & 1.36 & 74.89 & 0.048 & 1.14 & 0.838 \\
185000 & 1.36 & 78.55 & 0.050 & 1.12 & 0.823 \\
250000 & 1.58 & 80.43 & 0.051 & 1.28 & 0.810 \\
\hline
\end{tabular}

the experimental part of this paper, the required correction can be easily applied, in the case of fractions, if one neglects the variation of resolving power with elution volume in the restricted range covered by a single fraction. Table 2 shows the results for seven fractions with $M_{w}$ values between 6800 and 250000 . The correction factor to be applied decreases regularly with increasing molecular weight, as shown in the last column. It may be estimated from these data that for commercial, polydisperse PVC samples, in the usual range of molecular weights, the real value for $M_{w} / M_{n}$ is about 10 per cent lower than the uncorrected value calculated from the chromatogram. However, in view of the other sources of experimental error, it seems hardly worthwhile to apply this correction in a systematic manner.

\section{Effect of polydispersity on intrinsic viscosity}

The intrinsic viscosity of polydisperse PVC samples is lower than the corresponding value for a fraction of same weight-average molecular weight. 
This effect of polydispersity is illustrated in Figure 13 for cyclohexanonesolutions; with THF as a solvent the effect is similar and of the same order of magnitude. If the intrinsic viscosity-molecular weight relationship is given by:

$$
[\eta]=K M^{\prime \prime},
$$

the intrinsic viscosity, for a polydisperse sample, can be derived from Equation 43 by application of the usual addition rule and is given by the following expression:

$$
[\eta]=\left[\Gamma(h+v+1) /(h+1)^{v} \Gamma(h+1)\right] K M_{w}^{v}
$$

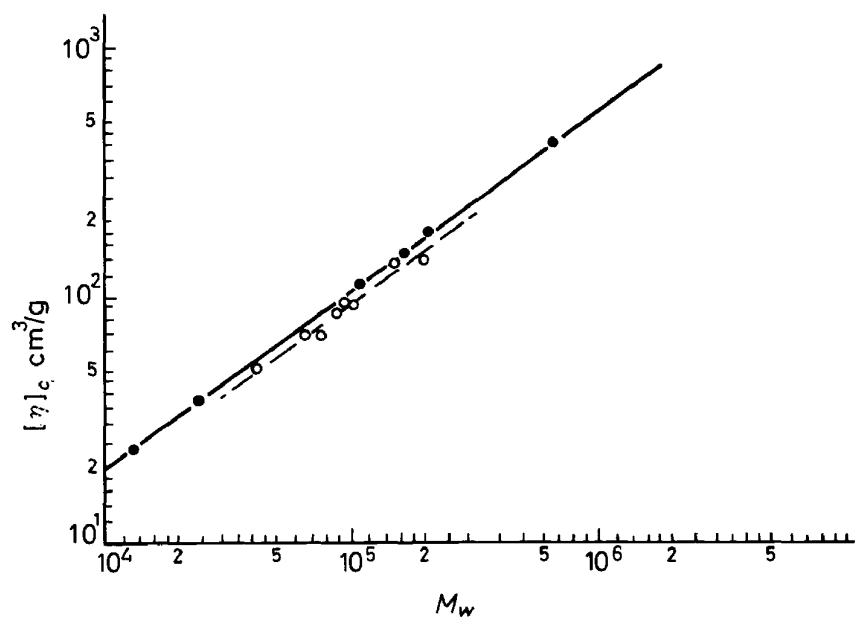

Figure 13. Empirical relationship between intrinsic viscosity in cyclohexanone and weight average molecular weight. PVC fractions (Equation 39); - - - - commercial PVC samples

For fractions with a $M_{w} / M_{n}$ ratio of $1.2(h=5)$, the correction factor in Equation 47 is equal to 0.985 for solutions in THF $(v=0.760)$ and 0.983 for cyclohexanone solutions $(v=0.725)$, which is within the limits of experimental error. However, for polydisperse samples with $M_{w} / M_{n}=2,(h=1)$, the correction factors calculated from Equation 47 are equal to 0.957 and 0.952 respectively, in excellent agreement with the experimentally found, average value 0.954 for THF.

Consequently, the viscosity-average molecular weight $M_{v}$ calculated from the intrinsic viscosity, by means of the relationships given by Equations 8 or 39 will be somewhat smaller than the average $M_{w}$ for polydisperse PVC samples. For most commercial PVC resins with a $M_{w} / M_{n}$ ratio in the order of 2, the $M_{w} / M_{v}$-ratio will be equal to about 1.1 , if THF or cyclohexanone is used as solvent Its exact value can be calculated from the observed MWD by means of the usual expression:

$$
M_{w} / M_{v}=\left(\Sigma w_{i} M_{i}\right) /\left(\Sigma w_{i} M_{i}^{v}\right)^{1 / v}
$$




\section{SOLUTION PROPERTIES OF POLYVINYL CHLORIDE}

The values for the weight fraction $w$ to be inserted into Equation 48 can be directly read from the chromatogram and their evaluation does not require the knowledge of any analytical expression characteristic of the MWD. As mentioned before, however, calculated values for the characteristic averages $M_{n}, M_{v}$ and $M_{w}$ are in fair agreement, for most commercial PVC samples, with those derived from the analytical expression, Equation 43, with a value for $h$ in the order of unity. Deviations from this ideal MWD may be expected to become more apparent in higher moments of the distribution function, as has been discussed in the foregoing section.

\section{Radius of gyration of polydisperse PVC samples}

The determination of the average radius of gyration of polymer molecules in dilute solution by means of the light-scattering technique is only feasible, with a reasonable degree of accuracy, if the molecular dimensions are relatively large. According to our experience the molecular size of commercial PVC samples, in the usual range of molecular weights, is too small to allow a reliable evaluation of the radius of gyration by means of this technique. On the other hand, the fact that the MWD may be adequately represented in many cases by the most probable distribution, Equation 43 with $h=1$, constitutes a favourable factor because the reciprocal particle scattering function $P^{-1}(\theta)$ may be considered then as a linear function of $\sin ^{2}(\theta / 2)^{58,59}$. For fractionated samples of narrow MWD, this is no longer

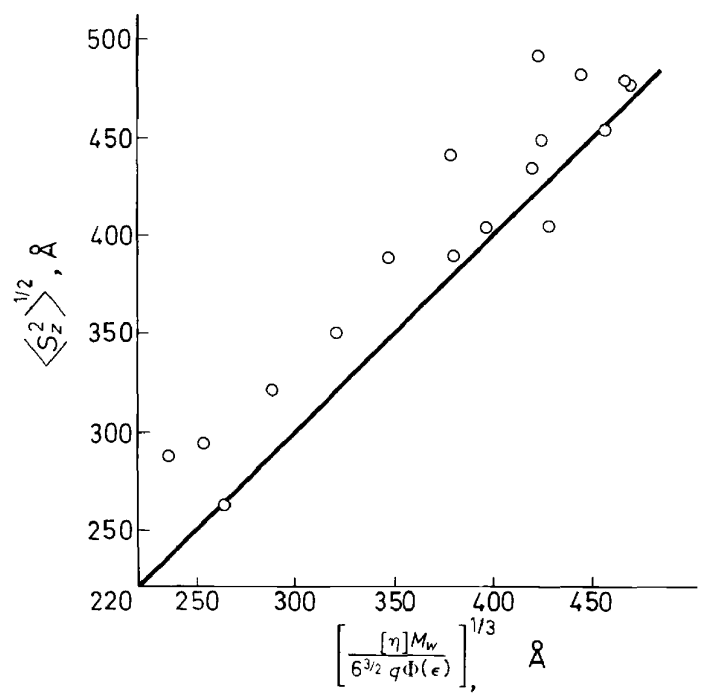

Figure 14. Experimental z-average radius of gyration for polydisperse PVC samples as a function of calculated radius of gyration (Equations 49 and 50)

true and the average radius of gyration has to be calculated from the initial slope, the evaluation of which is not very accurate.

For a number of experimental PVC samples, prepared in the laboratory with $M_{w}$ values in a range between 140000 and 450000 , the average radius 


\section{A. J. DE VRIES, C. BONNEBAT AND M. CARREGA}

of gyration has been determined from their Zimm-plots which could be adequately represented by straight lines. The results have been plotted in Figure 14 as a function of the $z$-average radius of gyration calculated from the intrinsic viscosity and the weight-average molecular weight by means of Equations 11 and 13 , assuming $\overline{S^{2}}=\bar{R}^{2} / 6$.

In order to take account of the polydispersity, we have assumed that the MWD is identical with the most probable distribution $(h=1)$ but preliminary investigations in our laboratory seem to indicate that at least some of these experimental polymers may have a wider MWD than commercial PVC resins of lower average molecular weight.

The calculated $z$-average radius of gyration is given by the following equation:

$$
\left\langle S_{z}^{2}\right\rangle^{\frac{1}{2}}=\left[\frac{[\eta] M_{w}}{6^{\frac{3}{2}} q \Phi(\varepsilon)}\right]^{\frac{1}{3}}
$$

the heterogeneity factor $q$ has been calculated from the following equation, due to Stockmayer ${ }^{60}$ :

$$
q=(h+1) \Gamma(h+v+1)\left[\Gamma(h+2) / \Gamma\left(h+\frac{8+2 v}{3}\right)\right]^{\frac{3}{2}} \Gamma(h+1)
$$

For $h=1$, and $v=0.76, q$ is equal to 0.47 .

Figure 14 shows clearly that the values for the radius of gyration deduced from the light-scattering measurements are, in general; significantly higher than those calculated from Equations 49 and 50. The method does not appear appropriate for obtaining accurate values for the average dimensions of polydisperse PVC molecules. The observed discrepancies may, however, partly be due to an underestimation of the heterogeneity of these experimental polymer samples.

\section{Long chain branching in PVC}

The possible occurrence of long chain branching in PVC has been discussed by several authors, most recently by Lyngaae-Jorgensen ${ }^{61}$ who has also published an extensive bibliography on this subject. The presence of short branches has been well established, in spite of the discrepancies between different authors as to the absolute value which are undoubtedly due to differences in interpretation of the infrared spectrum of the polyethylene samples obtained after the reduction of PVC with lithiumaluminium hydride $\left(\mathrm{LiAlH}_{4}\right)$. Based on the most reliable results reported in the literature, as well as on our own results, we may estimate that the total number of branches in commercial PVC samples will be, in general, less than ten per molecule. Most of these branches are short ones whose origin may be ascribed to a 'backbiting' mechanism as suggested by Bovey and Tiers ${ }^{62}$ in analogy with the similar phenomenon supposed to occur in the polymerisation of ethylene.

Short branches are not expected to influence, appreciably, the molecular dimensions of the polymer molecules, nor their hydrodynamic behaviour but this is not the case for long branches which exert a non-negligible effect on the characteristic molecular parameters of polymers ${ }^{63,64}$. In particular, 


\section{SOLUTION PROPERTIES OF POLYVINYL CHLORIDE}

the intrinsic viscosity of a polymer molecule containing long branches will be less than the intrinsic viscosity of a linear molecule of identical molecular weight. The curvature of empirical intrinsic viscosity-molecular weight relationships sometimes observed in the region of the higher molecular weights has led some authors to assume that PVC molecules of high molecular weight may contain long branches. Our work shows, however, that PVC fractions with $M_{w}$ values up to 650000 still obey the same relationship between intrinsic viscosity and molecular weight as the one found in the region of lower molecular weights. It seems, therefore, probable that the anomalous behaviour observed by other authors was caused, in reality, by the presence of supermolecular aggregates in the investigated solutions of high molecular weight PVC fractions.

The excellent experimental accuracy of our empirical relationship between intrinsic viscosity and molecular weight, as well as its good agreement with other equations reported in the literature, also seems to indicate that the number of long branches must be relatively small and rather independent of the conditions of polymerization. Moreover, in a few cases only we have measured intrinsic viscosity values for experimental PVC samples which were about 10 per cent higher than those calculated from the empirical relationship for fractions. If we assume that in those exceptional samples

Table 3. Intrinsic viscosity and melting point of reduced PVC samples compared with HDPE and LDPE fractions

\begin{tabular}{lccc}
\hline Polymer sample & $M_{w} \times 10^{-3}$ & {$[\eta]_{\text {dec }}^{13{ }^{\circ} \mathrm{C}} \mathrm{cm}^{3} / \mathrm{g}$} & Melting point* ${ }^{*} \mathrm{C}$ \\
\hline reduced PVC & 17 & 62.8 & 131.0 \\
& 20 & 67.5 & 131.0 \\
& 29 & 90.3 & 131.5 \\
& 33 & 90.3 & 131.0 \\
& 34 & 90.9 & 131.0 \\
HDPE & 35 & 99.7 & 132.5 \\
LDPE & 54 & 125.0 & 135.5 \\
& 65 & 162 & 135.0 \\
& 40 & 64.0 & 113 \\
& 80 & 80.0 & 114 \\
\hline
\end{tabular}

* Measured by D. S. C. (du Pont de Nemours 900 Thermal Analyser) heating rate $15^{\circ} \mathrm{C} / \mathrm{min}$

long branches were completely absent we might deduce from the ZimmStockmayer-Kilb theory that all PVC fractions, used in the study reported in the first part of this paper, would contain on average less than two long branches per molecule. This estimate may be considered as an upper limit, as shown by the following additional evidence. The reduction of PVC by means of $\mathrm{LiAlH}_{4}$ results in the formation of a crystalline polyethylene whose melting point has been found to be identical with the melting temperature of high density polyethylenes ${ }^{61}$ and much higher than that of LDPE fractions of the same molecular weight (Table 3).

The identity in molecular structure of PVC and high density polyethylene is also confirmed by the results of a recent study in our laboratory on the 


\section{A. J. DE VRIES, C. BONNEBAT AND M. CARREGA}

relationship between intrinsic viscosity and molecular weight of polyethylene samples obtained by reduction of commercial PVC polymers. Some of the results obtained so far are illustrated in Figure 15. The solid line in this figure represents the intrinsic viscosity-molecular weight relationship for linear polyethylene (HDPE) in decalin, at $135^{\circ} \mathrm{C}$, given by Henry ${ }^{65}$, which

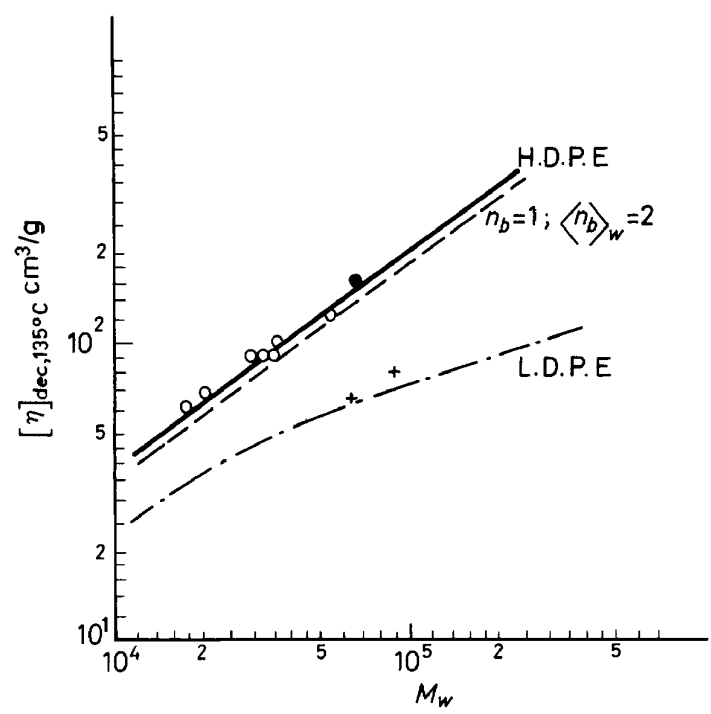

Figure 15. Intrinsic viscosity in decalin of reduced PVC samples as a function of weight-average molecular weight ___ empirical relationship for $\mathrm{HDPE}^{65} ;-\cdot-.-.-$ empirical relationship for LDPE ${ }^{66 ; 67,68}$; - - calculated relationship for HDPE containing one long branch per molecule; O reduced PVC samples; HDPE fraction; + LDPE fractions.

has been confirmed by numerous workers, also in our laboratory (one experimental result on an HDPE fraction, in the region of molecular weights of interest in this study, is indicated in the figure). The chain line represents the intrinsic viscosity-molecular weight relationship for branched, low density polyethylene (LDPE) based on the results of various authors ${ }^{66-68}$ Since the latter results were obtained in trichlorobenzene, a small correction factor has been applied equal to the ratio of intrinsic viscosities of HDPE in decalin and trichlorobenzene, respectively. It is obvious from Figure 15 that the presence of long branches in LDPE has an appreciable effect on the intrinsic viscosity compared to the value of the same parameter for linear polyethylene. The intrinsic viscosity of the polyethylene samples obtained by reduction of a series of polydisperse PVC resins ${ }^{69}$ is in excellent agreement with the values calculated from the empirical relationship for HDPE. The weight-average molecular weight of these samples has been determined by light-scattering, using 1-chloronaphthalene as solvent $(\mathrm{d} n / \mathrm{d} c=-0.196$ at $140^{\circ} \mathrm{C}$ ). The dotted line drawn in Figure 15 represents the theoretical relationship between intrinsic viscosity and weight-average molecular weight for 


\section{SOLUTION PROPERTIES OF POLYVINYL CHLORIDE}

polyethylene molecules containing, on the average, one long branch per molecule. This relationship has been calculated from the Zimm-StockmayerKilb theory for trifunctional branch points, by assuming that the weightaverage number of branch points is twice as large as the number-average ${ }^{70}$. Taking into account the possible experimental errors, the data shown in Figure 15 seem to indicate that the existence of more than one long branch per molecule in commercial PVC samples is not very probable and that the structure of PVC molecules, in this respect, is comparable to that of HDPE. The possible formation of a limited number of long chain branches may be supposed to occur, then, in the later stages of the polymerization process at relatively high degrees of conversion ${ }^{71}$.

\section{CONCLUSION}

A detailed study of the dilute solution properties of PVC is still hindered by the rather restricted choice of solvents. THF and to a lesser degree, cyclohexanone are the only solvents actually known to be able to furnish real molecular solutions characterized by a strong polymer-solvent interaction. The different extrapolation procedures proposed in the literature, in order to calculate the unperturbed dimensions of polymer molecules, must be handled with care and do not lead, necessarily, to an unambiguous result in the case of PVC. In spite of this uncertainty the unperturbed dimensions calculated in this way are of the same order of magnitude as those found for other vinyl polymers.

The light-scattering technique is an excellent tool for the determination of average molecular weights in a very broad range but, in the limited range covered by the actually commercialized PVC resins, exclusion chromatography appears to be the most appropriate technique for providing rapid and detailed information on the molecular weight distribution. Variations in MWD detected by means of the latter technique are usually small for commercial PVC samples and should be interpreted with precaution, in particular when the chromatographic system has not been properly calibrated with respect to selectivity and resolving power.

Finally, since the MWD in a large number of commercial PVC resins can be adequately represented, in a first approximation, by the 'most probable' distribution, the traditional practice of characterizing those resins by the value of their viscosity in dilute solution may be expected to yield relatively accurate estimates of the weight-average molecular weight.

\section{References}

1 P. Kratochvil Collection Czech. Chem. Commun. 30, 1119 (1965).

2 M. Bohdanecký, K. Šolc, P. Kratochvil, M. Kolínský, M. Ryska and D. Lím. J, Polymer Sci. A2, 5, 343 (1967).

3 P. Kratochvil, V. Petrus, P. Munk, M. Bohdanecký and K. Solc, J. Polymer Sci, G, 16, 1257 (1967).

4 P. Kratochvíl, M. Bohdanecký, K. Solc, M. Kolinský, M. Ryska and D. Lím. J. Polymer Sci. C, 23, 9 (1968).

5 D. Kockott. Kolloid-Z. 198, 17 (1964).

6 J. A. Juijn, J. H. Gisolf and W. A. de Jong Kolloid-Z. 235, 1157 (1969).

7 M. Bohdanecký. Collection Czech. Chem. Commun. 34, 2065 (1969). 


\section{A. J. DE VRIES, C. BONNEBAT AND M. CARREGA}

8 P. J. Flory. J. Chem. Phys. 17, 223 (1949).

9 R. Gautron and C. Wippler. J. Chim. Phys. 58, 754 (1961).

10 H. Benoit Intern. Symp. on Macromolecules, IUPAC, Leiden 1970 (to be published).

11 C. Wippler and G. Scheibling. J. Chim. Phys. 51, 201 (1954).

12 B. H. Zimm. J. Chem. Phys. 16, 1093 (1948).

13 J. C. Moore, J. Polymer Sci. A2, 835 (1964).

${ }^{14}$ K. O. Pedersen. Arch. Biochem. Biophys. Suppl. 1, 157 (1962).

15 E. F. Casassa and Y. Tagami. Macromol. 2, 14 (1969).

${ }^{16}$ A. J. de Vries, M. Le Page, R. Beau and C. L. Guillemin. Anal. Chem. 39, 935 (1967).

${ }_{17}$ M. Le Page, R. Beau and A. J. de Vries. J. Polymer Sci. C 21, 119 (1968).

18 R. Beau, M. Le Page and A. J. de Vries. Appl. Polym. Symp. 8, 137 (1969).

19 Z. Grubisic, P. Rempp and H. Benoit. J. Polymer Sci. B_5, 753 (1967).

20 A. E. Hamielec and W. H. Ray. J. Appl. Polymer Sci. 13, 1319 (1969).

21 A. E. Hamielec. Eighth Intern. Seminar on Gel Pemeation and Liquid Chromat. Prague, 1970; J. Appl. Polymer Sci. 14, 1519 (1970).

${ }^{22}$ L. H. Tung and J. R. Runyon. J. Appl. Polymer Sci. 13, 2397 (1969).

${ }^{23}$ A. J. de Vries, Eighth Intern. Seminar on Gel Permeation and Liquid Chromat. Prague, 1970 (to be published).

${ }^{24}$ L. H. Cragg and H. Van Oene. Can. J. Chem. 39, 203 (1961).

${ }^{25}$ G. W. Schulz and F. Blaschke. J. Prakt. Chem. 158, 130 (1941).

26 M. L. Huggins. J. Am. Chem. Soc. 64, 2716 (1942).

27 F. Ibrahim and H. G. Elias. Makromol. Chem. 76, 1 (1964).

${ }^{28}$ F. W. Ibrahim. J. Polymer Sci. A3, 469 (1965).

29 G. C. Berry. J. Chem. Phys. 46, 1338 (1967).

30 J. Congard. J. Soc. Statist. (Paris) 92, 284 (1951).

31 M. Freeman and P. P. Manning J. Polymer Sci. A2, 2017 (1964).

32 P. Debye and A. M. Bueche. J. Chem. Phys. 16, 573 (1948).

33 P. J. Flory. Principles of Polymer Chemistry Cornell Univ. Press, Ithaca, N.Y. (1953).

34 O. B. Ptitsyn and Yu. E. Ejzner. Zh. Tekhn. Fiz. 29, 1117 (1959).

${ }^{35}$ M. V. Volkenstein. Conformational Statistics of Polymeric Chains Interscience Publ. NewYork, 1963.

36 P. J. Flory. Statistical Mechanics of Chain Molecules Interscience Publ New-York, 1969.

37 B. H. Zimm, W. H. Stockmayer and M. Fixman. J. Chem. Phys. 21, 1716 (1953).

${ }^{38}$ P. J. Flory and T. G. Fox Jr. J. Am. Chem. Soc. 73, 1904 (1951).

${ }^{39}$ M. Kurata and W. H. Stockmayer. Fortschr. Hochpolymer. Forsch. 3, 196 (1963).

40 M. Kurata, W. H. Stockmayer and A. Roig. J. Chem. Phys. 33, 151 (1960).

41 M. Sato, Y. Koshiishi and M. Asahina. Polymer Letters 1, 233 (1963).

42 W. H. Stockmayer and M. Fixman. J. Polymer Sci. C 1, 137 (1963).

43 M. Kurata and H. Yamakawa. J. Chem. Phys. 29, 311 (1958).

44 W. Burchard. Makromol. Chem. 50, 20 (1961).

45 J. M. G. Cowie. Polymer 7, 487 (1966).

46 M. Bohdanecký, V. Petrus and P. Kratochvil. Collection Czech. Chem. Commun. 34, 1168 (1969)

47 W. R. Krigbaum. J. Polymer Sci. 18, 315 (1955).

48 B. H. Zimm. J. Chem. Phys. 14, 164 (1946).

49 M. Bohdanecký. Polymer Letters 3, 201 (1965).

50 T. A. Orofino and P. J. Flory. J. Chem. Phys. 26, 1067 (1957).

51 G. V. Schulz and H. Baumann, Makromol. Chem. 114, 122 (1968).

52 G. Kegeles, S. M. Klainer and W. F. Salem. J. Phys. Chem. 61, 1286 (1957).

53 W. H. Stockmayer. Makromol. Chem. 35, 54 (1960).

54 E. F. Casassa. Polymer 3, 625 (1962).

55 G. V. Schulz Z. Physik. Chem. B43, 25 (1939).

56 J. C. Moore and J. G. Hendrickson. J. Polymer Sci. C8, 223 (1965).

57 D. Goedhart and A. Opschoor. J. Polymer Sci. A2, 8, 1227 (1970).

58 H. Benoit. J. Polymer Sci. 11, 507 (1953).

59 H. Benoit, A. M. Holzer and P. Doty. J. Phys. Chem. 58, 635 (1954).

60 A. R. Shultz, J. Am. Chem. Soc. 76, 3422 (1954).

61 J. Lyngaae-Jorgensen. Seventh Intern. Seminar on Gel Permeation Chromat. Monaco (1969).

${ }^{62}$ F. Bovey and G. Tiers. Chem. Ind. (London) 42, 1826 (1962).

63 W. Stockmayer and B. H. Zimm. J. Chem. Phys. 17, 1301 (1949). 


\section{SOLUTION PROPERTIES OF POLYVINYL CHLORIDE}

64 B. H. Zimm and R. W. Kilb, J, Polymer Sci. 37, 19 (1959).

65 P. M. Henry. J. Polymer Sci. 36, 3 (1959).

66 E. E. Drott, Fourth Intern. Seminar on Gel Permeation Chromat. Miami (1967); J. Polymer Sci. A2, 8, 1373 (1970).

67 P. Crouzet, A Martens and P. Mangin, Seventh Intern. Seminar on Gel Permeation Chromat. Monaco (1969).

68 R. Panaris and R. Prechner, ibid.

69 M. Carrega, C. Bonnebat and G. Zednik. Anal. Chem. 42, 1807 (1970).

70 W. Graessly and H. M. Mittelhauser. J. Polymer Sci. A2, 5, 431 (1967).

71 M. Hlousek and J. Lanikova. J. Polymer Sci. C, 16, 935 (1967). 